\title{
SIMULATION OF RESIDUAL STRESSES IN SURFACE AND SUBSURFACE LAYER AFTER MACHINING
}

This article deals with non-destructive detection method of residual stress as analytical tool of expected distribution of residual stress in surface and sub-surface layers. Based on measurements, which can consists of cloud of points, lines or surface map of residual stress, we can simulate potential distribution of residual stress in surface and subsurface layers via mathematical-statistical procedures. Right identification of residual stress and its distribution can improve the prediction of failures and similar damage incidences due to workload over lifetime of components and also, it can be used as evaluation parameter of suitability of applied manufacturing technological operations.

Keywords: X-ray diffractometry, residual stress, non-destructive detection method, simulation of distribution.

\section{Introduction}

Residual stresses are an integral part of manufactured workpieces, whether they are introduced deliberately, as a part of the design, as a by-product of a process carried out during the manufacturing process, or are present as the product of the component's service history. Residual stresses have cumulative effect to the existing stresses in the workpieces as a result of service loads [1 and 2]. In practice, residual stress is stress which affects the entire volume of part or the majority of itself, i.e. macroscopic character. This includes the stress in infinitely thin or large area. It is important that violation of compactness of part causes the change in macro-geometry. Methods of machining, casting, forming, etc. can cause these changes. For full classification, it should be noted that residual stresses are called sometimes as technological stresses, because they arise from the action of technological processes during the producing of parts. Direction of residual stress (tension or compression) depends on the kind of deformation. Permanent residual stresses have the largest share on the functionality of part, and they cannot be detected by conventional methods [3 and 4].

Obviously, to realize the benefits of understanding the residual stresses in parts and structures, tools are needed to measure them. Several techniques are available, with varying degrees of sophistication. Some of them are rather limited in their application, but one stands out as having widespread applications and being readily available [5 and 6$]$.

X-ray diffraction is a specific method that can measure residual stress quantitatively in crystalline and semi-crystalline materials, which include virtually all metals and their alloys, and most ceramic materials. It is a non-destructive detection technology in many applications, and is widely accepted by the engineering community, being the subject of SAE and ASTM publications, which provide reliable sources of information on methods to ensure repeatability and reliability in the results of measurements. Because individual measurements are nondestructive, they can be replicated to demonstrate their statistical reliability [7, 8 and 9].

This article is focused on determining stress characteristics and their simulated prediction of distribution in surface and subsurface layers.

\section{Residual stress}

Stress conditions are the ones of demonstrations of used machining technologies. After manufacturing process, they remain in parts and constructions and they operate continuously even without load. Their impact significantly affects the functionality of machined surfaces. [2, 10 and 11].

\footnotetext{
* Andrej Czan, Michal Sajgalik, Jozef Holubjak, Marianna Piesova, Tatiana Czanova

Department of Machining and Manufacturing Technology, Faculty of Mechanical Engineering, University of Zilina, Slovakia

E-mail: andrej.czan@fstroj.uniza.sk
} 


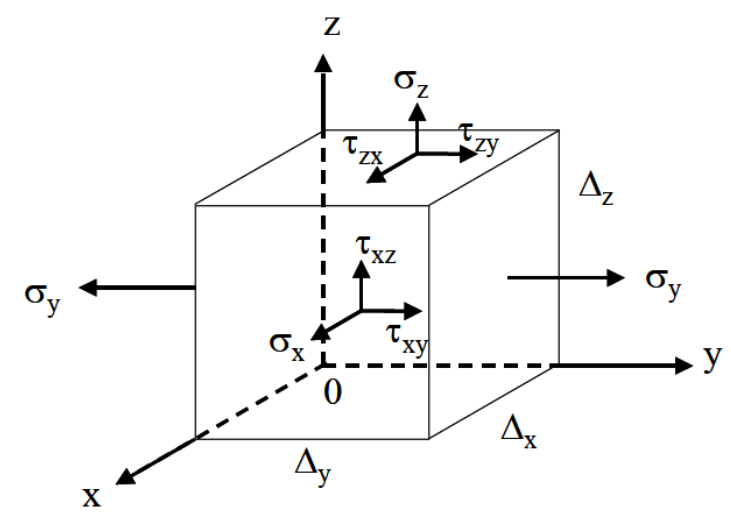

Fig. 1 Scheme of triaxial stress acting on an elemental unit cube [10]

Normal stress is defined as the stress acting normal to the surface of a plane; the plane on which these stresses are acting is usually denoted by subscripts. For example, consider the general case as shown in Fig. 1, where stresses acting normal to the faces of an elemental cube are identified by the subscripts that also identify the direction in which the stress acts, e.g., $\sigma_{x}$ is the normal stress acting in the $x$ direction. Since $\sigma_{x}$ is a normal stress it must act on the plane perpendicular to the $x$ direction. The convention used is that positive values of normal stress denote tensile stress, and negative values denote a compressive stress [10, 12, and 13].

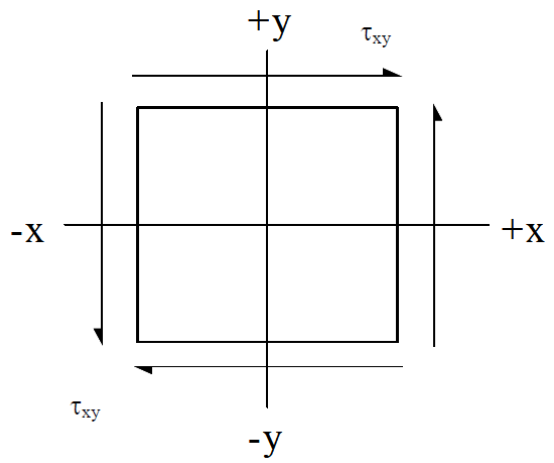

(a)

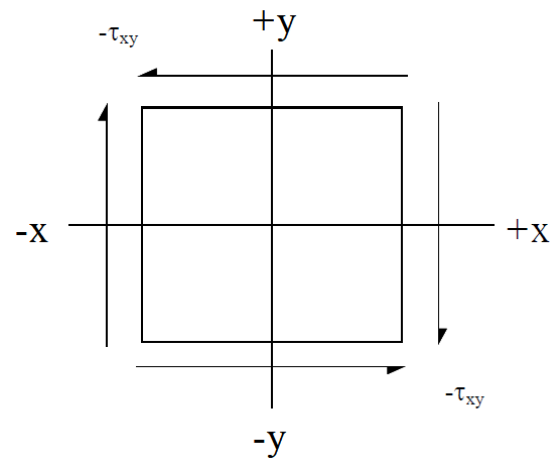

(b)

Fig. 2 Sign convention for shear stress - (a) Positive, (b) negative [10]
A shear stress acts perpendicular to the plane on which the normal stress is acting. Two subscripts are used to define the shear stress, the first denotes the plane on which the shear-stress is acting and the second denotes the direction in which the shear stress is acting. Since a plane is most easily defined by its normal, the first subscript refers to this. For example, $\tau_{z x}$ is the shear stress on the plane perpendicular to the $z$-axis in the direction of the $x$-axis. The sign convention for shear stress is shown in Fig. 2, which follows Timoshenko's notation. That is, a shear stress is positive if it points in the positive direction on the positive face of a unit cube. It is negative if it points in the negative direction of a positive face. All of the shear stresses in (a) are positive shear stresses regardless of the type of normal stresses that are present, likewise all the shear stresses in (b) are negative shear stresses [10 and 14].

\section{Principles of measurement of residual stress by X-ray diffraction}

The residual stress determined using X-ray diffraction is the arithmetic average stress in a volume of material defined by the irradiated area, which may vary from square centimeters to square millimeters, and the depth of penetration of the X-ray beam. The linear absorption coefficient of the material for the radiation used governs the depth of penetration, which can vary considerably. However, in iron, nickel, and aluminium-based alloys, $50 \%$ of the radiation is diffracted from a layer approximately $0.005 \mathrm{~mm}$ deep for the radiations generally used for stress measurement. This shallow depth of penetration allows determination of macro and microscopic residual stresses as functions of depth, with depth resolution varying from 10 to 100 times larger than potentiality of other methods. Although in principle virtually any inter-planar spacing may be used to measure strain in the crystal lattice, the availability of the wavelengths produced by commercial X-ray tubes limits the choice to a few possible planes. The choice of a diffraction peak selected for residual stress measurement impacts significantly on the precision of the method. The higher the diffraction angle, the greater the precision. Practical techniques generally require diffraction angles, $2 \theta$, greater than $120^{\circ}$ (Fig. 3) [8 and 15].

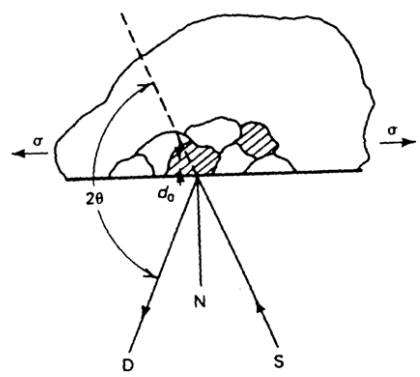

Fig. 3 Principles of X-ray diffraction stress measurement [8] 
Plane-stress elastic model X-ray diffraction stress measurement is confined to the surface of the sample. Electro-polishing is used to expose new surfaces for subsurface measurement. In the exposed surface layer, a condition of plane stress is assumed to exist. That is, a stress distribution described by principal stresses $\sigma_{1}$ and $\sigma_{2}$ exists in the plane of the surface, and no stress is assumed perpendicular to the surface, $\sigma_{3}=0$.However, a strain component perpendicular to the surface $\varepsilon_{3}$ exists as a result of the Poisson's ratio contractions caused by the two principal stresses (Fig. 4) [3].

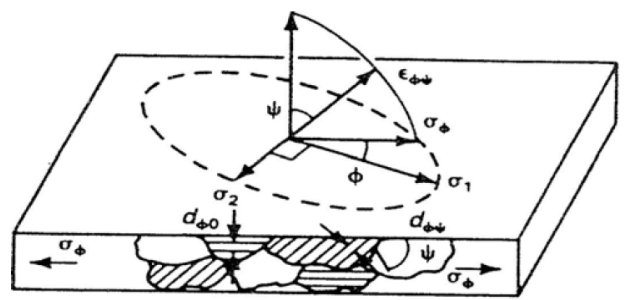

Fig. 4 Plane-stress elastic model [8]

\section{Experiment conditions}

Experiment was performed on constructional non-doped steel $\mathrm{C} 56 \mathrm{E} 2$, which is used for production of bearing rings and other rolling parts of bearings. This steel is also suitable for production of shafts, gear wheels, pivots etc. It is characterized by worse weldability, and it is used mostly for production of parts with higher wear resistance.

Sample for the experiment was machined by turning technology on $\mathrm{CNC}$ turning center. We monitored the residual stress with constant cutting speed $\left(v_{c}=200 \mathrm{~m} \mathrm{~min}^{-1}\right.$ for roughing and $v_{c}=250 \mathrm{~m} . \mathrm{min}^{-1}$ for finishing $)$ and depth ( $a_{p}=3 \mathrm{~mm}$ for roughing and $a_{p}=0.5 \mathrm{~mm}$ for finishing) and increasing values of feed ( $f=0.17 \div 0.55 \mathrm{~mm}$ for roughing and $f=0.05 \div 0.1 \mathrm{~mm}$ for finishing).

The measuring of residual normal and shear stress was performed with Proto XRD diffractometer (Fig. 5) and electro- chemical polisher for removing the minimal layers of surface up to $200 \mu \mathrm{m}$.

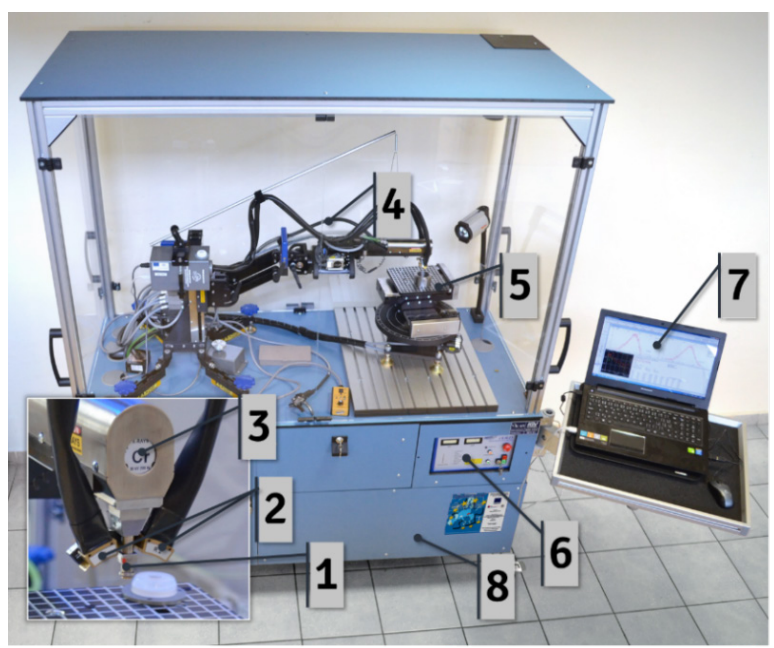

Fig 5 X-ray diffraction residual stress measurement system (stationary: 1 - collimator; 2 - two detectors for diffraction cone;

3-X-ray tube; 4 -Cobralink ${ }^{\circledR}$ flexible arm; 5 - positionable and rotary table; 6 - control unit; 7 - PC with software; 8 - laboratory stand

From the theory of elasticity the relationship between residual stress $(\sigma)$ and strain $(\varepsilon)$ on the sample surface under plane stress is given by the Bragg equation, $\lambda=2 d \sin \theta$, relating incident $\mathrm{X}$-ray wavelength $(\lambda)$, lattice inter-planar spacing $(d)$ and diffraction angle $(\theta)$ (Fig. 6). The direction of maximum residual stress, which can be tensile or compressive, is assumed to occur in the cutting direction during most machining operations.

The residual stress field at a point, assuming a condition of plane stress, can be described by the minimum and maximum normal principal residual stresses, the maximum shear stress, and the orientation of the maximum stress relative to some reference direction. The minimum stress is always perpendicular to the maximum. The maximum and minimum normal residual stresses, shown as $\sigma_{1}$ and $\sigma_{2}$ in Fig. 4, and their orientation relative to a
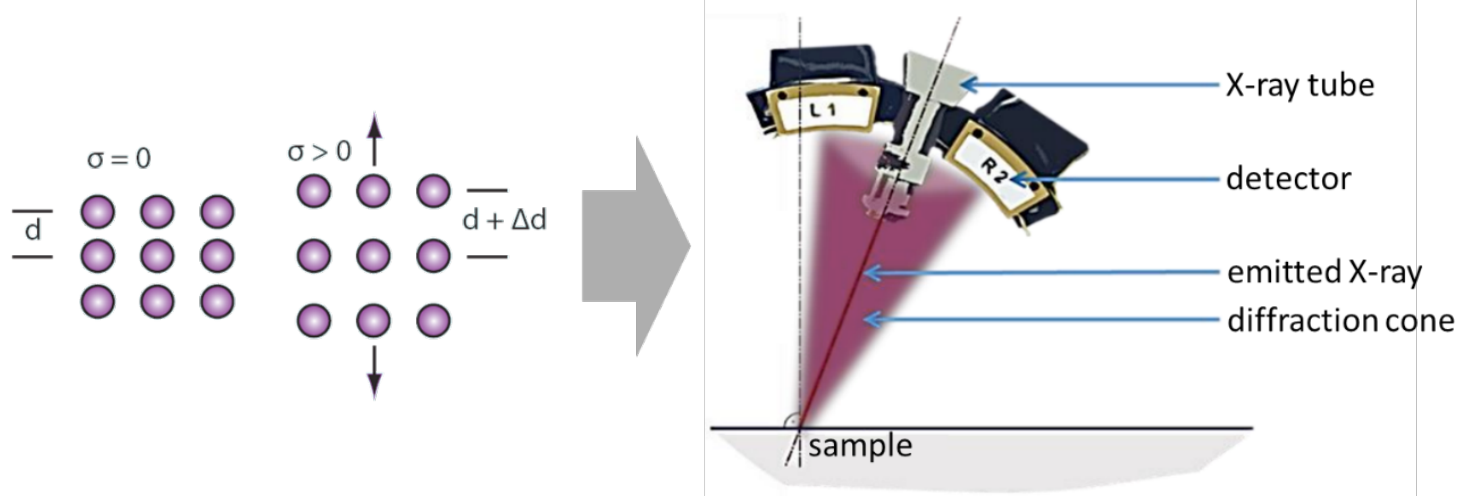

Fig. 6 Principle of measuring of residual stress by X-ray diffractometry based on Brag's Law 
reference direction can be calculated along with the maximum shear stress using Mohr's circle for stress, if the stress $\sigma_{\phi}$ is determined for three different values of $\phi$.

\section{Experimental results}

Input data for simulation were measured as cloud of points or square map $(10 \times 10 \mathrm{~mm})$ consisting of points regularly disposed within it. Measurements were made in the surface layer (depth of $0 \mathrm{~mm}$ ) and regular subsurface layers up to $200 \mu \mathrm{m}$. In the following figures we can see the selected courses of normal residual stress through the measured depth in one place (at one point).

Selected Figs. 7 and 8 present the courses of residual stress through the measured depth. Almost all the cases, with the given cutting conditions, have a similar course. In the surface layer and higher subsurface layers, the residual stress had compressive character. With the increasing depth, these residual stresses decreased, or changed character to the tensile stress.
From measured data, we computed via STATISTICA software the simulation of distribution of normal residual stress in three directions: direction of cutting speed, direction of cutting feed (or speed of cutting feed) and direction of depth. Subsequently, 3D graphs of these distributions were generated.

3D simulation of distribution of normal residual stress after roughing operations shows changes of normal residual stress in surface layer in direction of cutting speed and cutting feed (Fig. 9a). No step changes can be seen: normal residual stresses are in the range between $175 \mathrm{MPa}$ and $245 \mathrm{MPa}$ with compressive character. Roughing operations with cutting depth $3 \mathrm{~mm}$ are relatively suitable for next finishing operations without inheritance of visible signs of possible rise of errors. Simulation into the depth (Fig. 9b) of part material shows residual stress with tensile character in deeper layers and a very large range of values (from 292MPa of compressive residual stress up to $74 \mathrm{MPa}$ of tensile residual stress). The risk of errors increased, but in

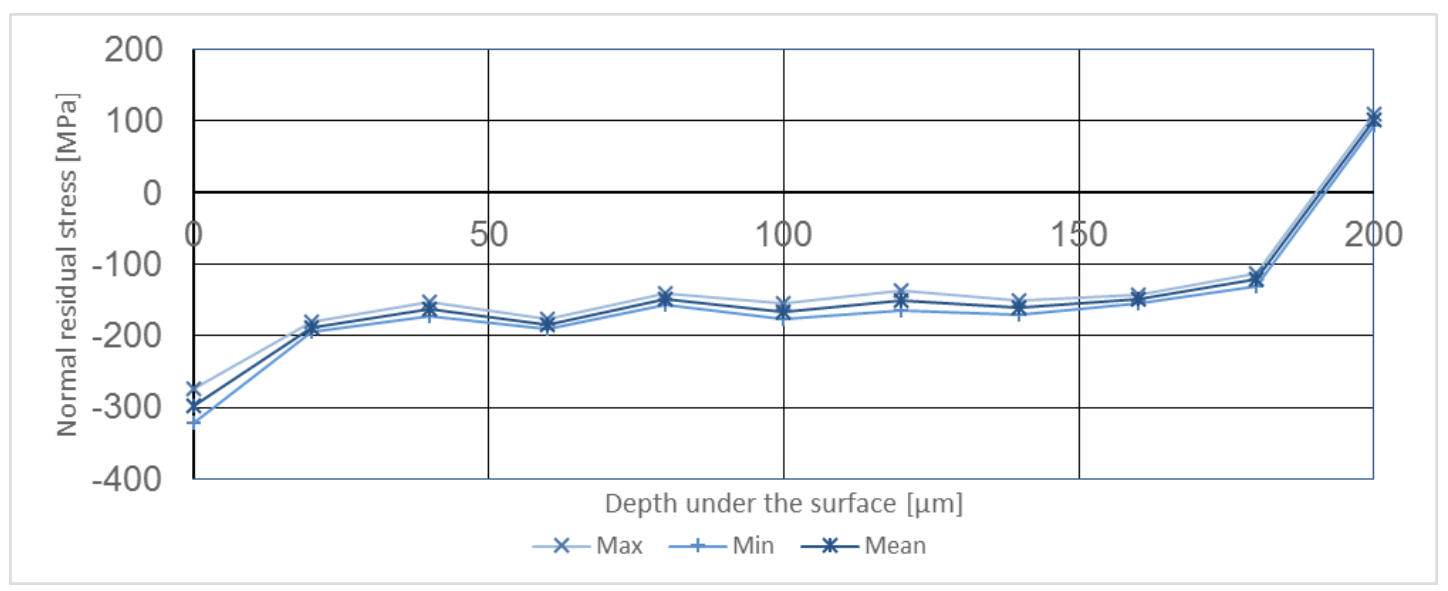

Fig. 7 Measured values of normal residual stress into the depth after roughing

(cutting conditions: $v_{c}=200 \mathrm{~m} \cdot \mathrm{min}^{-1}, f=0.17 \mathrm{~mm}, a_{p}=3 \mathrm{~mm}$ )

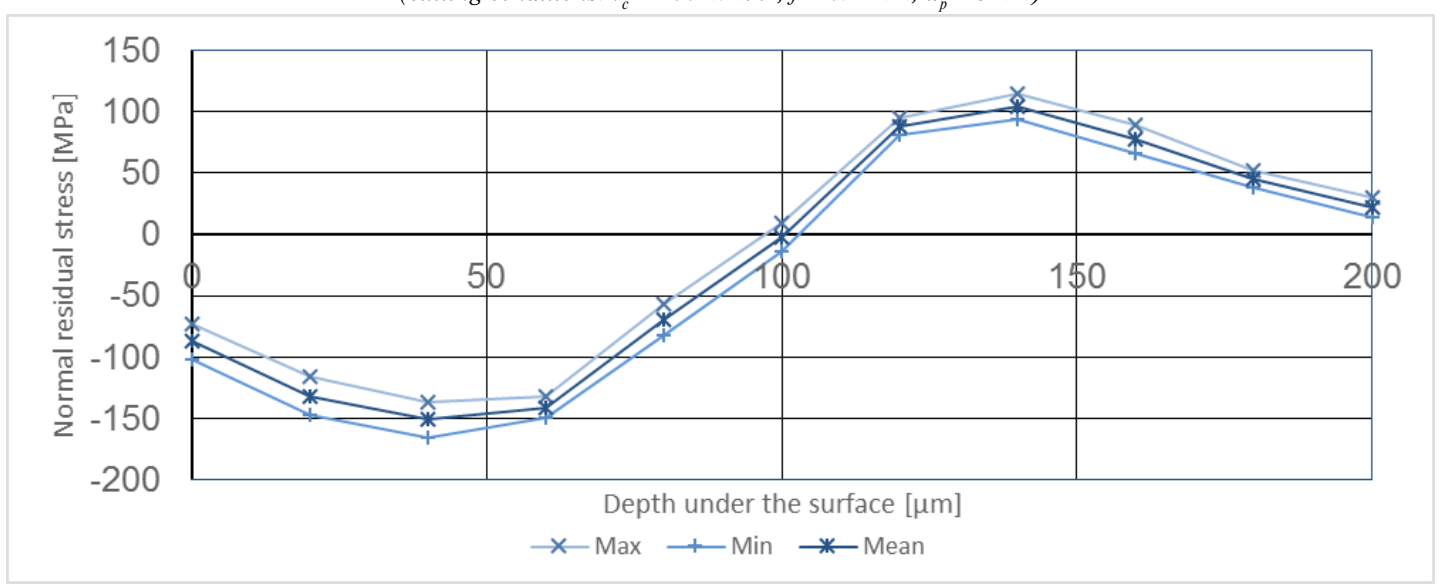

Fig. 8 Measured values of normal residual stress into the depth after finishing (cutting conditions: $v_{c}=250 \mathrm{~m} \cdot \mathrm{min}^{-1}, f=0.05 \mathrm{~mm}, a_{p}=0.5 \mathrm{~mm}$ ) 


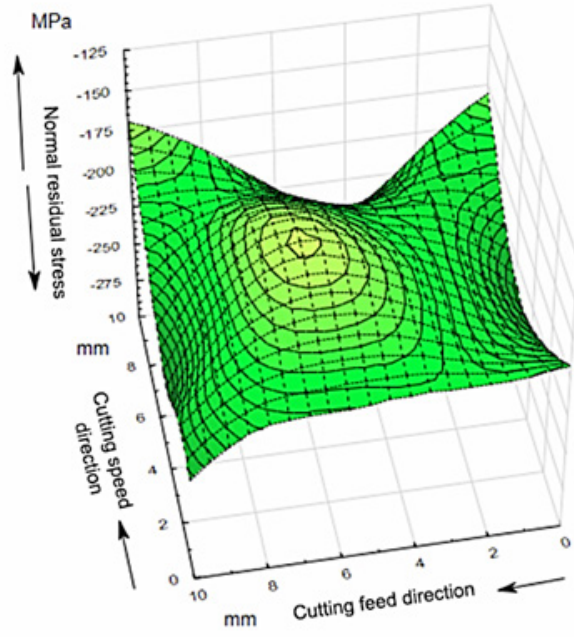

a)
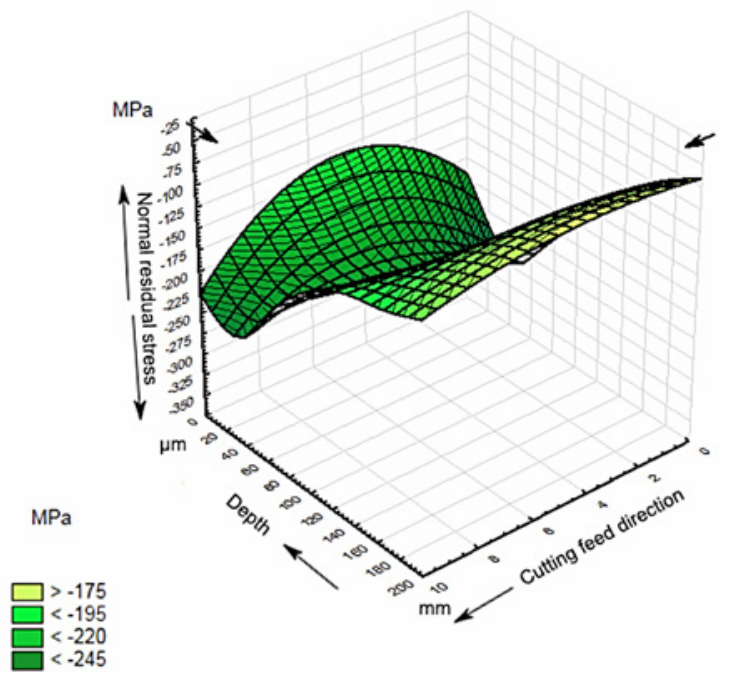

b)

Fig. 9 Simulation of distribution of normal residual stress in various directions after roughing operations (cutting conditions: $v_{c}=200 \mathrm{~m}^{\mathrm{min}} \mathrm{m}^{-1}, f=0.35 \mathrm{~mm}, a_{p}=3 \mathrm{~mm}$ )

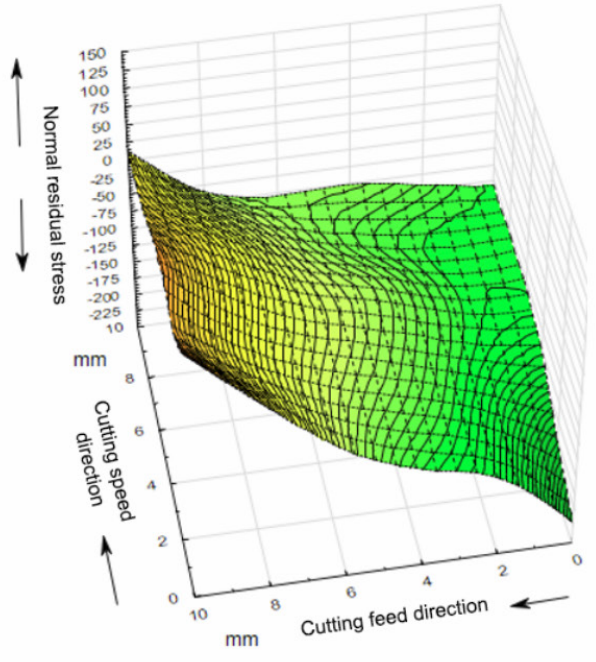

a)

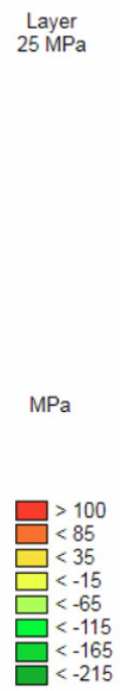

$<-165$

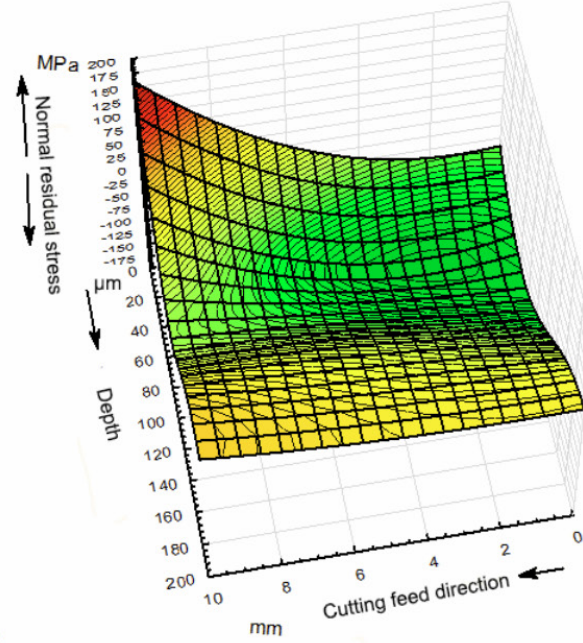

b)

Fig. 10 Simulation of distribution of normal residual stress in various directions after roughing operations (cutting conditions: $v_{c}=250 \mathrm{~m} \cdot \mathrm{min}^{-1}, f=0.075 \mathrm{~mm}, a_{p}=0.5 \mathrm{~mm}$ )

many causes it can be improved by finishing operations or other treatments of surface.

Simulation of distribution of normal residual stress, for finishing operations, shows rise of tensile residual stress with direction of cutting feed (Fig. 10a). It can be caused by gradual increase in the volume of extruded material by the cutting tool due to relatively low cutting depth $\left(a_{p}=0.5 \mathrm{~mm}\right)$. Simulation into the depth (Fig. 10b) shows increased appearance of residual stress with tensile character. The range of normal residual stress on surface layer and deepest measured layer $(200 \mu \mathrm{m})$ is again very large. It is not suitable for final state of part. This problem can be solved via improvements of surface and subsurface layers by applying other finishing methods such as shot peening.

\section{Discussion and conclusion}

Measurement of residual stress is a topical problem by which we can predict the functional properties of parts. Some destructive methods allow to measure residual stress in subsurface layers, 
but due to its principles, they are not so detailed and accurate. Principles of X-ray diffraction can measure the residual stress at microstructure levels and so push the boundaries of measuring in this area. Automation of this device allows to measure not only individual points or small lines, but we can obtain cloud of points or maps of residual stress distribution. Through the mathematicalstatistical procedures, we can minimalize the number of required measured points and so create sufficiently precise simulations of residual stress distribution. And finally, from this data we can see a detailed course of residual stress depending on cutting conditions into the depth of machined material. In presented experiments, we can see that the course of residual stress can be changed dramatically in the range of several micrometres. By applying these simulations, we can design suitable cutting conditions and so to minimalize the rise of potential errors, which can cause formation of cracks and subsequent failures.

\section{Acknowledgments}

This article was funded by the University of Zilina project OPVav-2009/2.2/04-SORO number (26220220101) - "Intelligent system for nondestructive technologies on evaluation for the functional properties of components of X-ray diffraction."

\section{References}

[1] GRIFFITHS, C. A.: Closing the Loop on Product Integrity on Bearings with Engineered Source Approval, Split Ballbearing Features, Company Newsletter, 1989.

[2] GANEV N., KRAUS I.: X-ray Diffraction Measurement of Residual Stresses, Material Structure, vol. 9, No. 2, 2002.

[3] TIITTO, K. et al.: Testing Shot Peening Stresses in the Field, The Shot Peener, vol. 4, 1991, ISSN 1069-2010.

[4] CEP, R., PETRU, J., ZLAMAL, T., VALICEK, J., HARNICAROVA, M., JANASEK, A., CEPOVA, L.: Influence of Feed Speed on Machined Surface Quality. Proc. of $22^{\text {nd }}$ Intern. Conference on Metallurgy and Materials, pp. 1033-1038, 2013, ISBN 978808729441-3

[5] PALA, Z., KOLARIK, K., GANEV, N., CAPEK, J.: Study of Residual Stress Surface Distribution on Laser Welded Steel Sheets, 51 ${ }^{\mathrm{st}}$ Annual of the Intern. Scientific Conference on Experimental Stress Analysis, EAN 2013

[6] SAPIETOVA, A., SAGA, M., NOVAK, P.: Multi-software Platform for Solving of Multibody Systems Synthesis, Communications Scientific Letters of the University of Zilina, vol. 14, No. 3, 43-48, 2012, ISSN 1335-4205.

[7] PREVEY, P. S.: X-ray Diffraction Residual Stress Techniques, Metals Handbook 10, Metals Park: American Society for Metals, pp. 380-392, 1986.

[8] FITZPATRICK, M. E. et al.: Determination of Residual Stresses by X-ray Diffraction. Measurement Good Practice, No. 52, 2005, National Physical Laboratory, Teddington.

[9] STANCEKOVA, D., SEMCER, J., HOLUBJAK, J., DRBUL, M.: Machinability of Nano-structured Biomaterials for Dental Implants. Communications - Scientific Letters of the University of Zilina, vol. 16, No. 3A, 2014, pp. 96-100, 2014, ISSN 1335-4205.

[10] BREZINA, M., KUPCA, L.: Stress Corrosion Cracking of Austenitic Stainless Steel in a Nuclear Power Plant Environment, Environment inducted cracking of materials, Department of Structural Analysis : VUJE Inc, Trnava, pp. 431-436, 2008.

[11] CZAN, A., TILLOVA, E., SEMCER, J., PILC, J.: Surface and Subsurface Residual Stresses after Machining and Their Analysis by X-ray Diffraction. Communications - Scientific Letters of the University of Zilina, vol. 15, No. 2, 2013, pp. 69-76, ISSN 1335-4205

[12] NAPRSTKOVA, N., HOLESOVSKY, F.: Admeasurement of Grinding Wheel Loss at FPTM. 24 ${ }^{\text {th }}$ Intern. colloquium Advanced manufacturing and repair technologies, pp. 159-164, 2007, ISBN 978-80-7194-962-6.

[13] VASILKO, K., PILC, J.: New Technological Knowledge of the Rotary Turning Tool, J. Manufacturing Technology, vol. 13, No. 4, December 2013, pp. 571-575, ISSN: 1213-2489.

[14] CEP, R., JANASEK, A., PETRU, J., CEPOVA, L., CZAN, A., VALICEK, J.: Hard Machinable Machining of Cobalt-based Superalloy, Manufacturing Technology XIII/13, UJEP : Usti n. Labem, pp. 226-231, 2013, ISSN 1213-2489.

[15] CZAN, A., SAJGALIK, M., MARTIKAN, A., MRAZIK, J.: Observation of Dynamic Processes in Cutting Zone when Machining Nickel Alloys. Communications - Scientific Letters of the University of Zilina, vol. 16, No. 3A, pp. 161-168, 2014, ISSN 1335-4205. 